\title{
O ENSINO NA NATAÇÃO: UTILIZAÇÃO DE TUTORES PARA TREINOS EM ATLETAS COM DEFICIÊNCIA FÍSICA
}

\author{
Paulo T. Nazar, Lilian Cristina Gomes Nascimento, Juliana A. P. Schuller, \\ Cléria Maria Lobo Bittar, Maria Georgina Marques Tonello \\ Universidade de Franca \\ Franca, São Paulo \\ E-mail: paulo.nazar@unifran.edu.br, liliangomes@hotmail.com,juliana_schuller@yahoo.com.br, \\ cleria.bittar@unifran.edu.br, gina@ginatonello.com.br
}

Resumo: A natação adaptada é um dos esportes mais importantes para pessoas com deficiências físicas. Este estudo teve como objetivo discutir a ação de tutores e avaliar a percepção de atletas com deficiências. Participaram do estudo oito atletas, idade de 18 a 55 anos, com deficiências físicas. Participaram dos treinos de natação tutores durante oito semanas. Os atletas com deficiências físicas participaram de um grupo focal. Os resultados encontrados foram de 3 categorias diferentes a respeito da experiência com a tutoria na natação adaptada. $O$ estudo concluiu que a tutoria foi apresentada como uma experiência positiva e apresentaram também críticas em relação a experiência. Algumas competências foram apresentadas para o desenvolvimento dos tutores para proporcionar uma prática mais eficaz.

Palavras-chave: pessoas com deficiência, natação, preceptoria, atletas.

\section{TEACHING IN SWIMMING: TUTORS OF USE FOR TRAINING IN PHYSICAL DISABILITY ATHLETES}

Abstract: The adapted swimming is one of the most important sports for people with disabilities. The objective of this study was discuss the actions of preceptorship and evaluating the perception of athletes with disabilities. Participated eight athletes age 18-55 years old, with physical disabilities. Participated in swimming training preceptorship for eight weeks. Athletes with physical disabilities participated in a focus group. The results were 3 different categories of the experience with tutoring in adapted swimming. The study found that athletes was presented as a positive experience and also had criticisms of the experience. Some skills were presented for the development of preceptorship to provide a more effective practice.

Keywords: disabled people, swimming, preceptorship, athletes.

Recebido em 28/11/2016. Publicado em 31/12/2016. 


\section{INTRODUÇÃo}

Toda perda ou anormalidade de uma estrutura, função psicológica, fisiológica ou anatômica, é considerada deficiência física. A incapacidade é determinada como toda restrição ou falta da capacidade de realizar uma atividade na forma ou na medida em que se considera normal a um ser humano. O impedimento é uma situação desvantajosa para um determinado indivíduo, em consequência de uma deficiência ou de uma incapacidade, que limita ou impede o desempenho de um papel considerado normal, levando-se em consideração idade, sexo, fatores sociais e culturais (DA CUNHA, 2001).

As principais causas que levam às deficiências são os transtornos congênitos e perinatais, decorrentes da falta de assistência ou de assistência inadequada às mulheres na fase reprodutiva; as doenças transmissíveis e crônicas não transmissíveis; as perturbações psiquiátricas; o abuso de álcool e de drogas; a desnutrição; os traumas e as lesões, principalmente nos centros urbanos mais desenvolvidos, onde são crescentes os índices de violências e de acidentes de trânsito (BRASIL, 2009).

A Classificação Internacional de Funcionalidade, Incapacidade e Saúde (CIF, 2004), no contexto de saúde determina que, deficiências são problemas (comprometimentos) nas funções ou nas estruturas do corpo, tais como um desvio importante ou uma perda. Funções do corpo englobam tanto as funções fisiológicas quanto as psicológicas e estrutura do corpo, são as partes anatômicas como órgãos, membros e seus componentes. Atividade é a execução de uma tarefa ou ação por um indivíduo. Participação é o envolvimento de um indivíduo numa situação da vida real. Limitações da atividade são as dificuldades que um indivíduo pode ter na execução de uma atividade. Restrição na participação se caracteriza como os problemas que um indivíduo poder enfrentar, quando está envolvido em situações de seu cotidiano. Fatores ambientais constituem no ambiente físico, social e atitudinal em que as pessoas vivem e conduzem sua vida.

De acordo com o Decreto no 5.296 (BRASIL, 2004), o Ministério da Saúde define como deficiência física uma alteração completa ou parcial de um ou mais segmentos do corpo humano, apresentando-se sob a forma de paraplegia, paraparesia, monoplegia, monoparesia, tetraplegia, tetraparesia, triplegia, triparesia, hemiplegia, hemiparesia, ostomia, amputação ou ausência de membro, paralisia cerebral, nanismo, membros com deformidades congênita ou adquirida. 
A amputação é definida como uma ausência, retirada parcial ou total de um ou mais membros. Na retirada parcial, a preocupação da equipe médica é preservar o máximo de coto possível, facilitando desta forma o encaixe e a movimentação de uma eventual prótese. No caso da amputação total ocorrendo a desarticulação do membro afetado, as limitações motoras serão maiores e a utilização de prótese provavelmente um pouco mais restrita. Paralisia cerebral é uma condição resultante de lesão encefálica, eminentemente motora, não devendo ser confundida com a deficiência intelectual. Na maioria dos casos resulta do processo de hipóxia que caracteriza como uma redução no fornecimento de oxigênio às células e anoxia, definida como a parada total deste suprimento às células (GREGUOL, 2010).

Mattos (1994) sugere a classificação da deficiência em relação à natureza, ao tempo de duração e a evolução dos distúrbios motores. Quanto à natureza divide-se em ortopédicos e neurológicos. No ortopédico, refere-se aos acometimentos de músculos, ossos e articulações e aos neurológicos, referem-se às deteriorações do sistema nervoso central, como é o caso de lesão medular.

Quanto ao tempo de duração determinam-se congênitos ou adquiridos e quanto à evolução, se identificam como progressivos (esclerose múltipla, distrofia muscular), permanentes (paralisia cerebral, lesão medular) ou crônicos (artritre). A lesão na medula espinhal se apresenta como uma grave síndrome incapacitante, determinada pela paralisia de segmentos e um défit sensitivo (superficial e profundo). Caracteriza-se pelas disfunções vasomotoras, pelas alterações esfincterianas e disfunção sexual (GREVE; CASTRO, 2001).

Duas categorias funcionais fazem parte da lesão medular: a paraplegia e a tetraplegia. Paraplegia é determinada quando ocorre a paralisia parcial ou completa do tronco e de ambos os membros inferiores. A tetraplegia identifica-se como uma paralisia parcial ou completa dos quatro membros e tronco, incluindo músculos respiratórios. Paresia se apresenta como um comprometimento parcial com os movimentos limitados ou fracos, queda da força muscular, da precisão e da amplitude dos movimentos e sua resistência. A paralisia é causada por uma transecção completa, sem preservação de nenhuma função motora ou sensitiva (SCHMITZ, 2004).

Constitui-se num centro nervoso responsável por vários atos reflexos que controlam o tônus muscular, o trofismo, o controle esfincteriano, funções genitais e funções simpáticas como regulação térmica, respiração, circulação sanguínea e outros (GUYTON, 2006). 
As lesões em nível de medula espinhal podem ser de origem traumática, congênita ou infecciosa. As lesões traumáticas são as mais comuns como resultado de acidentes automobilísticos, por arma de fogo ou mergulhos em locais rasos. Identifica também as lesões congênitas como resultantes de um processo conhecido como Mielomeningocele e Espinha Bífida que consiste no fechamento de um ou mais arcos intervertebrais. O acidente vascular cerebral (AVC) é resultante de uma lesão ocorrida no cérebro em decorrência de uma interrupção na circulação sanguínea local. Sua origem pode ser de natureza isquêmica determinada como interrupção por entupimento dos vasos sanguíneos e hemorrágica que se caracteriza por interrupção ocasionada pela ruptura do vaso sanguíneo (GREGUOL, 2010).

A autora afirma ainda que as principais sequelas do ponto vista motor é a hemiplegia (paresia), incluindo perda de tônus muscular e no que se diz respeito à sensorial, alterações na percepção visual, auditiva e cinestésica. A coluna vertebral serve como duto e proteção para a medula espinhal, dividindo-se em medula cervical, dorsal, lombar e sacral (Figura 1). 
Figura 1. Funções e níveis da medula espinhal.

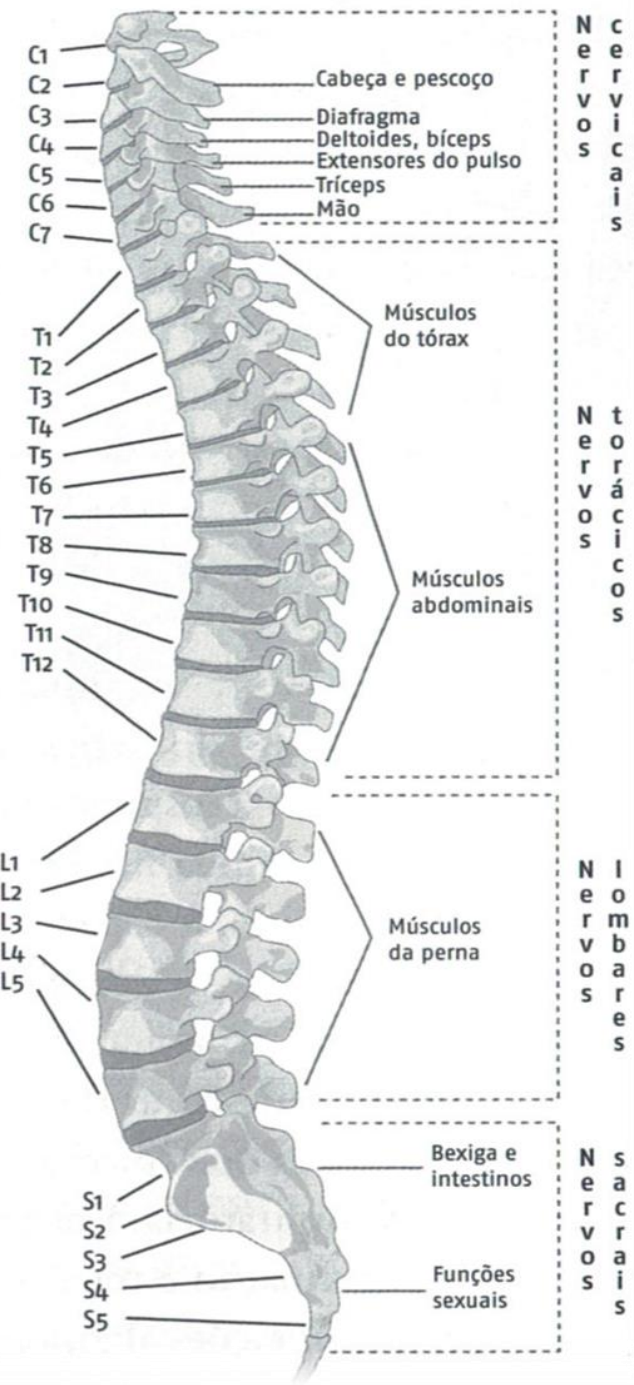

Outras ocorrências também podem levar à deficiência física como a espinha bífida, amputação, nanismo, malformação congênita, osteogênese imperfeita, distrofia muscular, poliomielite, paralisia cerebral, acidente vascular cerebral e lesões medulares. Cada deficiência acaba acarretando um tipo de comportamento e suscitando diferentes formas de reações, preconceitos e inquietações. As deficiências físicas, como paralisias e ausência de membros, causam imediatamente uma apreensão mais intensa, pois apresentam uma maior visibilidade e desta forma se tornam mais impactantes não somente ao próprio aluno com deficiência, mas também a todos os membros da família (MACIEL, 2000). 
Uma das doenças responsáveis por propiciar uma deficiência física é a Poliomielite, também conhecida como paralisia infantil, paralisia da manhã ou simplesmente pólio. Caracteriza-se, como uma doença inflamatória aguda causada por vírus, necrosando os neurônios motores de membros inferiores, manifestando no indivíduo de maneira que faça uso de cadeira de roda ou muletas, com a finalidade de facilitar seu deslocamento, ajudando-o em tarefas do cotidiano (ABE et al., 2011).

No conjunto das lesões proporcionadas por fatores externos, o Trauma Crânio Encefálico (TCE), destaca-se pela magnitude da incidência entre óbitos e feridos, evidenciando-se desta forma como uma das mais frequentes (MINISTÉRIO DA SAÙDE, 2000). É conceituado por Nitrini e Badeschi (2003) como qualquer agressão que venha acarretar uma lesão anatômica ou também um comprometimento funcional em nível cranial, meninges ou encéfalos, dividindo-se pela sua intensidade e pelo grau de lesão, podendo ser grave, moderado e leve.

Conforme salienta Maia (2010), os sentimentos mais comuns diante da deficiência são a negação e a revolta, observando que as pessoas com deficiências físicas podem vivenciar situações desagradáveis em níveis de preconceito, discriminação e afastamento, proveniente das diferenças corporais em relação à maioria dos indivíduos que fazem parte de seu convívio, contribuindo para uma autoestima negativa.

Configura-se como um mecanismo de negação social, todo preconceito ao indivíduo com deficiência, uma vez que todas as suas diferenças sejam ressaltadas como uma falta, carência ou impossibilidade. A condição de deficiência desperta (pela sociedade) reações de descriminação e preconceito, reforçando e fortalecendo a situação de exclusão. A informação e a comunicação são ferramentas eficazes para combater estas atitudes e ajudar a promover a equidade e o respeito à diversidade humana (GIL, 2004).

A sociedade demanda de uma estrutura de indivíduos fortes, que apresentem um corpo saudável e que sejam extremamente eficientes para a competição em que o mercado de trabalho exige. Determina também a importância de se comentar que a deficiência nem sempre está ligada à questão de hereditariedade, pois há casos de filhos que nascem sem a deficiência dos pais ou alguém da família que tenha uma deficiência e outros, em que não há a probabilidade de descendentes com deficiências (DA SILVA, 2006). 
Porém alguns esportes podem proporcionar autonomia de movimentos as pessoas com deficiência, como é o caso da natação adaptada, que além de ser um dos esportes com maior acessibilidade para grande parte das deficiências, contribui na reabilitação e na inclusão social, destacando que, indivíduos com deficiências físicas e que praticam natação, tendem a apresentar aumento em força muscular, flexibilidade, diminuição em percentual de gordura, aumento da autoestima e confiança, possibilitando a participação de forma mais efetiva das aulas/treinos (TOURNAKI \& CRISCITIELLO, 2003; LLORET, 2003).

A atividade na água ou o movimento de nadar significa um momento de liberdade e independência para o indivíduo com deficiência, momento este em que se consegue movimentar livremente, sem auxílio de bengala, muletas, pernas mecânicas ou cadeiras de rodas (GRASSELI e PAULA, 2002).

O número de praticantes em natação com algum tipo de afecção musculoesquelética vem se tornando cada vez maior em academias e clubes. Dentro deste contexto, Pereira e Garcez (2010) afirmam que, a natação adaptada em conjunto com as propriedades da água influencia no comportamento de pessoas com deficiência, sendo no aspecto fisiológico ou psicológico, desenvolvendo habilidades motoras que irão contribuir para as atividades de vida diária, eliminação do receio de seu próprio corpo, elevação da autoimagem, estimulo à independência, autonomia e socialização com outros grupos.

A natação adaptada além de ser um dos esportes com maior acessibilidade para grande parte das deficiências (LLORET, 2003) constitui uma ferramenta importante na reabilitação e inclusão social, destacando que, atletas com deficiências físicas que praticam natação podem apresentar aumento em força muscular, flexibilidade, diminuição em percentual de gordura, aumento da autoestima e confiança, possibilitando a participação de forma mais efetiva das aulas/treinos.

Para que essa população tivesse a oportunidade de aprender e desenvolver as habilidades básicas da natação adaptada como flutuabilidade, equilíbrio, sustentação, movimento corporal, deslocamento vertical e horizontal, o estudioso em deficiência física no meio aquático James Mc Millan, elaborou um método denominado Halliwick cujo objetivo principal é fazer com que o aluno tenha segurança no meio líquido, movimentação, deslocamento independente e autônomo (A.S.T., 2000). 
Para pessoas com deficiências físicas iniciantes em natação, a falta de equilíbrio proporcionada pela flutuabilidade e empuxo (força que atua de baixo para cima dentro da água), na fase de adaptação ao meio líquido, pode gerar uma maior insegurança ocasionando ansiedade, medo, dificuldade na respiração seja ela boca-nariz (inspira pela boca e expira pelo nariz) ou boca-boca (inspira e expira pela boca). Estes fatores fazem com que a pessoa com deficiência física tenha seu processo de adaptação ao meio líquido mais lento (CAMPION, 2000).

Assim que a flutuabilidade estiver dominada, a natação propriamente dita respectiva aos quatro nados, poderá ser introduzida no processo de aprendizagem, usando de técnicas tradicionais do ensino da natação. Porém este método sugere que estas habilidades natatórias sejam passadas, ensinadas em proporção de um para um (aluno/monitor) e que neste primeiro momento de adaptação ao meio líquido, não se use materiais que propiciem uma maior flutuabilidade como os chamados flutuadores, coletes e outros (A.S.T., 2000).

O monitor/instrutor deve se concentrar nas habilidades que o aluno dispõe e não nas deficiências físicas, por ele manifestada. As necessidades que cada aluno apresenta devem ser consideradas de maneira individualizada, mesmo que o aprendizado esteja acontecendo em grupo. Cada aluno com deficiência física domina as atividades aquáticas de maneira diferente e única, dependendo de seu potencial e grau de limitação. O professor deve ajudar e estimular para que este aluno aprenda os fundamentos necessários respeitando seu ritmo e sua maneira.

Por ser uma atividade que normalmente se apresenta, se pratica em grupo, estimula e favorece o desenvolvimento social daqueles que fazem as aulas/treinos. As aulas ministradas em grupos mistos propiciam em alguns casos uma igualdade de execução, até mesmo de competição entre os nadadores com e sem deficiência, com isso há um aumento na autoestima e na autoimagem do aluno com deficiência física, melhorando desta forma a capacidade de estabelecer contatos sociais (DE ALMEIDA, 2011).

Por se tratar de uma atividade física que envolve todo o corpo, a natação provoca diversas possibilidades de movimentação às pessoas com deficiência física, e a educação física adaptada se apresenta como um novo campo de atuação profissional. Academias, clubes têm apresentado um trabalho diferenciado no que se diz respeito a essa população especial, podendo também ser desenvolvido em caráter individualizado, em grupos pequenos e até mesmo em domicílio, 
tornando-se um leque de possibilidades na atuação do profissional de educação física (DE ALMEIDA; TONELLO, 2007).

Para o atleta com deficiência a atividade na água ou o movimento de nadar, significa um momento de liberdade e independência, vivenciando-se a oportunidade de se movimentar livremente, sem auxílio de bengala, muletas, pernas mecânicas ou cadeiras de rodas (GRASSELI; PAULA, 2002). Ocorrem mudanças afetivas em relação ao próximo e a si mesmo, mudanças cognitivas que contribuem para melhorar as demais atividades vivenciadas pelo atleta.

As atividades no meio aquático proporcionam a pessoa com deficiência física, superar as limitações, dominar os medos, os receios e melhorar o desempenho tanto na natação de sobrevivência (curtos deslocamentos), como na natação desportiva que abrange os quatro nados, objetivando sua participação em treinamento paralímpico (FREGOLANTE; DO PRADO, 2015).

Por tutoria entende-se o conjunto de ações cuja finalidade é articular a prática educativa comas experiências de campo, proporcionando uma aprendizagem que beneficie o desenvolvimento de competências e capacidades básicas, que potencialize o crescimento intelectual e autonomia, integrando comunicação, instrução e aspectos afetivos na relação entre alunos e tutores (TOURNAKI \& CRISCITIELLO, 2003; TOPPING, 2000; SOUZA et al, 2004). Por esta razão, a ação tutorial "se estende aos estudantes, professores e à própria universidade, todos se beneficiam" (GONZALEZ, 2008, p.71-88).

Autores como Tournaki e Criscitiello (2003, p. 22-29), entendem a tutoria como sendo "um método para efetivar a interação pedagógica entre tutores e alunos". Já Topping (2000) analisa como um processo interativo e sistemático realizado por um grupo de pessoas, sem que haja a necessidade de que seja realizada por professores, cujo resultado beneficia a ambos ampliando suas capacidades de comunicação.

A tutoria pode ser entendida como uma ação orientadora global, chave para articular a instrução e o educativo. O sistema tutorial compreende desta forma, um conjunto de ações educativas que contribuem para desenvolver e potencializar as capacidades básicas dos alunos, orientando-os a obterem crescimento intelectual e autonomia, e para ajudá-los a tomar decisões em vista de seus desempenhos e suas circunstâncias de participação como aluno (SOUZA et al., 2004). 
A tutoria se apresenta com aspectos significativos em relação ao reconhecimento social, concretizada por diversas práticas em diferentes domínios, sistemas de ensino (inclusive na formação inicial de professores), no ensino superior como ajuda aos estudantes, acompanhando e apoiando nos processos de aprendizagem. $O$ indivíduo que doa e oferece os seus conhecimentos e saberes, desempenha um papel de recurso humano, de guia para os indivíduos que expressam suas dificuldades, tratando-se de uma relação de aprendizagem individualizada e interativa (BARNIE, 2001).

A tutoria justifica-se e se consolida na possibilidade de elaborar coletiva e criticamente as experiências na fase de aprendizagem, identificando oportunidade ímpar para que professores e alunos se articulem de forma efetiva e organizada, produzindo conhecimentos, potencializando capacidades individuais e coletivas, entendendo os mecanismos de superação que norteiam a fases do aprendizado (MARTINS, 2007).

Salienta-se, todavia, que o papel da tutoria ultrapassa as dimensões acadêmicas, pois leva em consideração pensamentos e emoções dos tutoriados. Os tutores devem apoiar, dirigir, desafiar e acolher o aluno com deficiência a todo o momento que se fizer necessário (WALLACE e GRAVELLS, 2005).

A estratégia de se utilizar colegas tutores (peer tutor) compreende como um modelo em que colegas sem deficiência, apresentando a mesma idade ou mais velhos, propiciando suporte a um colega com deficiência, não somente em salas de aula, mas também nas próprias aulas de Educação Física (ORLANDO, 2010). A tutoria é considerada um dos procedimentos que pode ser desenvolvida nas aulas de educação física, pois os professores necessitam de uma estratégia que venham a ajuda-los adequadamente a lidar com a diversidade em um programa de inclusão (NABEIRO; LIEBERMAN, 2002).

O tutor aos poucos deve fazer com que os alunos percebam o quanto o trabalho colaborativo pode ajudar no processo ensino-aprendizagem, assumindo o papel de orientador e motivador e que o material didático e os métodos utilizados sejam adequados (BUCHANAN, 2000). Segundo Ferreira e Rezende (2003), o tutor deve acompanhar motivar, orientar e estimular a aprendizagem autônoma do aluno, fazendo-se uso de instrumentos e metodologias adequadas para facilitar o processo de aprendizagem. É importante ressaltar que para o indivíduo com deficiência o universo 
da inclusão vai além do princípio da igualdade de direitos e que se deve desenvolver um trabalho diferenciado, procurando evitar uma exclusão dentro do processo de inclusão. A questão não é se preocupar em tornar todos iguais, mas que todos encontrem seu espaço dentro desse processo de aprendizagem (CUNHA E ROSSATO, 2015).

É caracterizado ao tutor proporcionar uma atenção especial ao colega tutoriado, objetivando encorajamento e feedback, facilitando a busca de sucesso desta estratégia. O uso do feedback dos tutores em alunos com deficiência e que possuam uma baixa estima na realização das tarefas, servirá como estimulo e motivação às atividades propostas (FULK; KING, 2001). Tutores podem ser pais, outros adultos, irmãos ou voluntários. Nesse estudo a tutoria foi de alunos do curso de Educação Física devidamente matriculados. Para todo aquele que está sob os cuidados/orientação de um tutor, há necessidade que esta ação seja bem estruturada e cuidadosamente monitorada (AZEVEDO e NASCIMENTO, 2007).

O objetivo desse estudo foi discutir a ação de tutores e avaliar a pertinência da tutoria através da percepção de atletas com deficiências físicas sobre um programa de tutoria em natação adaptada.

\section{PERCURSO METODOLÓGICO}

Este estudo foi aprovado pelo Comitê de Ética em Pesquisa com Seres Humanos da Universidade de Franca (protocolo no 41942015.6.0000.5495) respeitando-se todo o conteúdo da Resolução $466 / 12$.

Trata-se de um estudo de natureza qualitativa que segundo Minayo (2013), trabalha com o universo de significados, motivos, aspirações, crenças, valores e atitudes, o que corresponde a um espaço mais profundo das relações, dos processos e dos fenômenos. Não se preocupa com representatividade numérica, mas sim com o aprofundamento da compreensão de um grupo social e de uma organização.

Participaram do estudo oito atletas com de ambos os sexos e deficiências físicas diversas conforme descritas na (Tabela 1.). E que fazem parte de uma equipe de natação adaptada e treinam regularmente em um programa promovido por uma universidade privada do interior de São Paulo, em parceria com a Prefeitura do Município. Abaixo a descrição dos participantes e os respectivos dados relativos à deficiência, idade, sexo, prática de natação e profissão. 
Tabela 1 - Caracterização dos participantes com relação a deficiência, idade, sexo, tempo de prática profissional de natação (anos), categoria natação paralímpica.

\begin{tabular}{|c|c|c|c|c|c|}
\hline $\mathrm{P}$ & Deficiência & Idade & Sexo & $\begin{array}{l}\text { Tempo de } \\
\text { prática }\end{array}$ & $\begin{array}{l}\text { Categoria } \\
\text { Natação }\end{array}$ \\
\hline P1 & $\begin{array}{l}\text { Máformação congênita de } \\
\text { membros inferiores e superiores }\end{array}$ & 41 & $\mathrm{~F}$ & 10 anos & S3 \\
\hline P2 & Sequela de Poliomielite & 55 & $\mathrm{~F}$ & 10 anos & S6 \\
\hline P3 & Sequela de Poliomielite & 40 & $\mathrm{~F}$ & 08 anos & $\mathrm{S} 4$ \\
\hline P4 & Epifisiolise & 21 & $\mathrm{~F}$ & 08 anos & S9 \\
\hline P5 & Artrite Séptica & 23 & $\mathrm{~F}$ & 07 anos & S9 \\
\hline P6 & $\begin{array}{l}\text { Má formação congênita de MMSS } \\
\text { esquerdo }\end{array}$ & 18 & M & 03 anos & S9 \\
\hline P7 & $\begin{array}{l}\text { Má formação congênita de MMSS } \\
\text { direito e esquerdo }\end{array}$ & 20 & M & 05 anos & S8 \\
\hline P8 & $\begin{array}{l}\text { Amputação transtibial de } \\
\text { MMIlesquerdo }\end{array}$ & 43 & M & 02 anos & S10 \\
\hline
\end{tabular}

Fonte: dados da pesquisa (2016).

O treinamento dos tutores que eram alunos do último ano do curso de Educação Física, foi realizado em duas sessões de oito horas em salas de aula com os seguintes conteúdos:

1) Deficiências físicas: causas, consequências e como seus níveis de comprometimento podem interferir nas habilidades motoras do indivíduo;

2) Teoria e prática da natação adaptada;

3) Orientação em tutoria, como atuar, funções, consequências, benefícios que a tutoria pode alcançar;

4) Os quatro nados (Crawl, Costas, Peito e Borboleta) foram transmitidos aos tutores conforme a deficiência apresentada pelos atletas participantes do estudo, as dificuldades que cada atleta em sua respectiva deficiência, poderia apresentar durante o nado. 
O programa de tutoria foi realizado duas vezes por semana, durante os treinos de natação adaptada, com duração de uma hora e meia, durante oito semanas. Os tutores participaram durante os treinos juntamente com o técnico da equipe.

Para realização do grupo focal foi utilizado um gravador digital e uma câmara filmadora digital ambos da marca Sony, objetivando uma análise fiel da fala dos atletas, sem a captação de imagens (vídeo) dos mesmos, propiciando desta forma tranquilidade aos participantes em discutir o tema proposto. O mediador observou o debate e assim obteve um conhecimento mais amplo sobre o que aconteceu com o grupo estudado (comportamentos, atitudes, linguagem e percepções). 0 processo de mediação abrangeu uma breve introdução, informando a importância da participação dos atletas no estudo, preparação, aprofundamento do conteúdo da discussão e fechamento do grupo. A discussão propiciada para o grupo focal esteve direcionada na experiência vivenciada pelos participantes sobre a atuação dos tutores na prática da natação adaptada.

Utilizou-se a técnica de grupo focal, considerado como a reunião de pessoas selecionadas para discutir e comentar sobre um tema específico (foco no tema), sob a coordenação de um moderador que por sua vez assume uma posição de facilitador do processo de discussão no qual se priorizam os aspectos psicossociais que emergem, enfatizando influências de opiniões sobre um determinado tema (GONDIM, 2003). A estratégia de grupo focal é uma técnica qualitativa que pode ser usada sozinha ou com outras técnicas qualitativas ou quantitativas, procurando aprofundar o conhecimento das necessidades dos entrevistados (VAUGHN, SCHUMM E SINAGUB, 1996).

Em seguida os discursos foram transcritos mantendo-se a fala original dos participantes e posteriormente analisadas, observadas em análise de conteúdo segundo a proposta de Bardin (2011) que a determina como, um conjunto de técnicas de análise das comunicações visando obter através de procedimentos sistemáticos, indicadores que permitam a inferência de conhecimentos relativos às produções das mensagens obtidas.

\section{RESULTADOS E DISCUSSÃO}

Encontraram-se 3 categorias diferentes a respeito da experiência com a tutoria na natação adaptada seguindo a proposta Bardin (2011): aqueles que disseram que esta foi uma experiência 
positiva. Tutoria: críticas à experiência. E a última categoria apresentada foi relacionada as competências e habilidades para praticar a tutoria.

\subsection{Caracterização dos sujeitos}

Para a maioria, a tutoria se revelou uma experiência positiva, que refletiu na melhora do desempenho e rendimento destes, como observa-se;

P1 - Muito bom pelo menos comigo foi excelente, deu pra mudar alguns nados, deu pra aperfeiçoar saídas, chegadas, pra mim foi muito bom.

P3 - Bom também gostei, o desempenho de cada um, me ajudaram também em algumas técnicas que eu tinha dificuldade.

P7- Intão, eu achei muito bom essa experiência sabe, principalmente no meu nado, na técnica do meu nado sabe, que não era tão bom.

P2 - Bom a pessoa que ficou responsável por mim (...), eu gostei muito do jeito que o menino trabalhou. Não me lembro do nome do menino agora, mas foi um rapaz assim, super atencioso. Eu tava com algumas dificuldades no nado de peito, ele corrigiu de um jeito gritando, falando alto para eu decorar né! (...) o T1 falou assim: "poxa faz seis anos que eu estou tentando fazer você nadar deste jeito e eu não sei o que o rapaz fez em você que em 2 dias você aprendeu". Então isto foi muito bom pra mim.

Os relatos estão em consonância com Rodrigues (2003), quando argumenta que a Educação Física, tem características positivas no processo de inclusão, seus conteúdos são flexíveis, a ponto de permitir liberdade no seu planejamento, bem como criar estratégias de ensino adequadas, que atendam ao contexto inclusivo.

Outros participantes destacaram ainda que a tutoria lhes serviu como elo entre estes e seus técnicos (professores);

P6 - Acho que o [professor T1] se aproximou mais da equipe, acho que ele estava meio afastado da gente, não chegava em ninguém. Esse trabalho achei, interessante por isso, igual o que P8 falou, "tinha gente que via, que não tava interessado em ajudar e estão agora".

P5 - Pra mim, melhorei muito nas técnicas, tava faltando essa aproximação [referindo-se ádistancia entre técnicos e atletas].

Observando este contexto de aproximação, Souza, Martins (2013), relatam como objetivo de seus estudos a compreensão dos liames entre a formação de professores em Educação Física e o 
processo de inclusão, apontando que possibilitam as aproximações entre esses dois contextos, já que a configuração de um professor inclusivo pressupõe a construção de um indivíduo atento com a diversidade do universo educativo.

\subsection{Tutoria: críticas à experiência}

Embora para a maioria dos participantes a tutoria tenha sido benéfica apresentando aspectos positivos, alguns apontaram críticas, sobretudo a atuação dos tutores.

P8 - É por outro lado, tevi alguns que deixaram a desejar, ficaram mais, mais afastados. Não tirava dúvida, é não demonstrava tanto interesse, faltou interesse, tá mais presente, mais ativo.

P6 - Mais não, com certeza tinha exercício que eles passavam...[refere-se á ação do tutor]

Outros ainda apontaram que a técnica utilizada não foi adequada para suas necessidades, ou que estavam erradas segundo suas percepções;

P1 - Que não era necessário [refere-se á alguns exercícios desnecessários passados pelos tutores]

P7 - Que também estava errado. A técnica do nado também...[indicando que alguns tutores, passavam de forma errada a técnica dos nados]

Apesar dos tutores terem sido treinados, muitos não apresentavam experiência com natação, o que pode ter proporcionado muitas vezes inseguranças em suas atitudes. $O$ estudo foi realizado também com atletas, já com alto índice de desempenho. A tutoria teria apresentado outros resultados se realizadas com iniciantes na natação.

As instituições do ensino superior devem procurar fomentar políticas que visem à promoção do bem-estar, da saúde mental e do desenvolvimento de competências pessoais no estudante, de forma a que este esteja mais "equipado" para enfrentar de maneira autônoma os sucessos e insucessos, os dilemas profissionais (SANTOS, VEIGA e PEREIRA, 2010).

\subsection{Competências e habilidades para praticar a tutoria}

Os participantes trouxeram informações a respeito do que entendiam sobre as habilidades e competências profissionais necessárias para a atuação de tutores no esporte paralímpico. Os relatos trazem suas impressões sobre o que o profissional deveria desenvolver para lidar com as 
necessidades de um atleta paralímpico. Na opinião dos participantes, a função de tutor de atletas paralímpicos, deveria ter a prerrogativa do desenvolvimento de algumas competências, como iniciativa e comprometimento;

P8 - Eu acho que faltou um pouco de iniciativa. A iniciativa de às vezes tirar uma dúvida com o técnico um e com o técnico dois, i questioná né, se o que ele tá fazendo tá certo, qualquer coisa às vezes muitos falavam o que os técnico falavam. Outros já tiveram a iniciativa de corrigi isso, corrigi aquilo e realmente depois eu fui observar que realmente, eu precisava melhorar aquilo que ele estava falando e outros não dava tanta bola.

P3 - A questão que o P1... usou a palavra comprometimento, num grupo sempre existiu e sempre vai existir. Os que comprometem a fazer, os que estão destinados e aqueles, que não tem aquele comprometimento por inteiro.

P4 - Igual assim, diria que os tutores que estavam comprometidos, ajudaram muito nos treinos porque quanto ao T2 e o T1, acaba ficando muita coisa só pros dois [referindo-se aos técnicos]. Cada um tem coisa pra fazer, são sobrecarregados. Quando eles vieram [referindo-se aos tutores], alguns ficavam em equipe num grupo, outros ficavam em outro grupo, então assim foi dividindo, deu pra todo mundo treinar legal.

A literatura corrente sobre a noção de competências assinala que ela é a capacidade de articular e mobilizar conhecimentos, habilidades e atitudes, colocando-os em ação para resolver problemas e enfrentar situações de imprevisibilidade em uma dada situação concreta de trabalho e em determinado contexto cultural (PERRENOUD, 1999).

O jovem adulto quando ingressa no Ensino Superior, vê-se confrontado com múltiplos desafios: um espaço institucional, com normas e tarefas acadêmicas que exigem o desenvolvimento de competências, com a necessidade de uma maior autonomia e envolvimento, associado, pela maioria dos jovens a um acréscimo de responsabilidade e de compromisso em várias dimensões (SECO et al 2005).

Outro ponto a destacar é a percepção da falta de habilidade e de informação por parte dos tutores-alunos, em lidar com as necessidades do atleta paralímpico. Na concepção de alguns, a dificuldade passa pela falta de preparo e de conhecimento técnico em lidar com o esporte adaptado e até mesmo com o aluno com deficiência.

P2 - Pra eles nós deficientes somos um bicho de sete cabeças né. Eles não sabem como lidar com a gente né! 
P4 - Que a P2 colocou que às vezes eles acham que a gente é tipo assim, um bicho de sete cabeças, a gente vê que até mesmo os próprios tutores cresceram né, porque no começo eles iam alongar a gente, tinham até receio, medo de como pegar, como alongar, se via que eles mesmos tinham...[referindo-se aos tutores] "vai que eu acabo machucando". Depois com o tempo, no final, já estava virando a gente pelo avesso.

Kamps et al. (2002) sugerem que os programas de tutoria incluam mediação social e acadêmica, grupos de colegas trabalhados em múltiplos lugares, recrutamento de novos colegas para generalizar os efeitos, modelação e reforço na mediação de colegas, argumento visual e técnicas de auto administração para realçar o ganho de habilidades sociais, fatos estes que demonstram ser importante tanto para a formação do tutor, como para o desenvolvimento das competências e habilidades necessárias para lidar com as necessidades e vicissitudes de cada grupo tutoriado.

\section{CONSIDERAÇÕES FINAIS}

Nesse estudo foi analisada a percepção de atletas com deficiências físicas sob a ação de tutores em natação adaptada. Encontraram-se três categorias diferentes no discurso dos atletas a respeito da experiência com a tutoria em natação adaptada: aqueles que disseram que esta foi uma experiência positiva, outros que fizeram críticas à experiência e a última categoria relacionada às competências e habilidades para praticar a tutoria.

A tutoria foi apresentada como uma experiência positiva de uma forma geral, no entanto, eles também apresentaram críticas em relação à experiência vivenciada. Por fim, apresentaram algumas competências e habilidades que deveriam ser desenvolvidas pelos tutores para proporcionar uma prática mais eficaz. Esse resultado também reflete o nível de expertise dos participantes, que já dominavam as técnicas dos nados. O processo de tutoria também deve ser investigado em iniciantes no esporte adaptado, esse enfoque poderá evidenciar questões relacionadas ao processo de ensino aprendizagem, que ficou limitado em nosso estudo.

Sugerimos que novos estudos investiguem também a percepção dos tutores, visando dessa forma ampliar os procedimentos para ensino e treino de pessoas com deficiências. Vale ressaltar por fim, que o processo de tutoria pode ser aplicado com qualquer deficiência, seja ela física, intelectual ou sensorial. Sendo dessa forma, um importante processo a ser aplicado nas aulas e treinos e investigado na literatura. 


\section{REFERÊNCIAS}

ABE, G. C, RAMOS, P. E.; FONTES, S. V.; YONAMINE, B.; MELLO, C. A. S.; QUADROS, A. J.; CHUN, W. P.; JIA, J. E.; SCHMIDT, B.; OLIVEIRA, A. S. B. Poliomielite e síndrome pós-polio pela medicina tradicional chinesa: da fisiopatologia ao diagnóstico. Revista Neurociências, p. 365-381, 2011.

A.S.T. - ASSOCIATION OF SWIMMING THERAPY. Natação para deficientes. 2 ed. São Paulo: Manole, 2000. p. 132.

AZEVEDO, N. R.; NASCIMENTO, A. T. B. Modelo de tutoria: construção dialógica de sentido(s). Revista Interacções, n. 7, p. 97-115, 2007.

Bardin, L. Análise de conteúdo. Tradução de Luís Antero Reto; Augusto Pinheiro. São Paulo: Edições 70, 2011. 281p.

BARNIE, G. Le tutoratdansL’enseignementeetla formation. Paris: L`Harmattan, 2001. p. 119120.

BRASIL. Ministério da Saúde. Coordenadoria Nacional para Integração da Pessoa Portadora de Deficiência. Acessibilidade. Deficiente físico. Secretaria Especial dos Direitos Humanos. Brasília: MS, 2004. 264 p.

BUCHANAN, E. A. Going the extra mile: serving distance education students. Jornal Of Distance Learning Administration, v. 3, n.1, 2000.

CAMPION, M. R. Hidroterapia, princípios e prática. São Paulo: Manole. 2000.

CIF- CLASSIFICAÇÃO INTERNACIONAL DE FUNCIONALIDADE, INCAPACIDADE E SAÚDE. OMS. Direcção-Geral da Saúde. Lisboa, 2004. Disponível em: <http://www.inr.pt/uploads/ docs/cif/ClF_port_\%202004.pdf>. Acesso em: 10 mar. 2016.

CUNHA, R.; ROSSATO, M. A singularidade dos estudantes com deficiência intelectual frente ao modelo homogeneizado da escola: reflexões sobre o processo de inclusão. Revista Educação Especial, v. 28, n. 53, p. 649-664, 2015.

DA CUNHA, E. A. Programa de ação mundial para as pessoas com deficiência. Brasília: Corde, 2001.

DA SILVA, L. M. O estranhamento causado pela deficiência: preconceito e experiência. Revista B

DE ALMEIDA, P. A. et al. Efeitos da prática da natação adaptada sobre o perfil bioquímico e o estado de condicionamento físico de indivíduos com lesão medular. Medicina (Ribeirão Preto. Online), São Paulo, v. 44, n. 4, p. 377-388, dec. 2011.

DE ALMEIDA, P. A.; TONELLO, M. G. M. Benefícios da natação para alunos com lesão medular. Lecturas: Educación Física y Deportes, n. 106, p. 4, 2007.

FERREIRA, M. M.; REZENDE, R. S. O trabalho de tutoria assumido pelo programa de educação a distância da Universidade de Uberaba: Um relato de experiência. In: EMINÁRIO NACIONAL ABED DE EDUCAÇÃO A DISTÂNCIA, v. 1, 2003. Anais...Uberaba, MG. 2003.

FREGOLENTE, G.; DO PRADO JUNIOR, M. V. A Inclusão da natação na vida da pessoa com deficiência: uma análise a partir da teoria ecológica do desenvolvimento. Revista da Associação Brasileira de Atividade Motora Adaptada, v. 16, n. 1, 2015.

FULK, B. M.; KING, K. Classwide peer tutoring at work. Teaching Exceptional Children, v. 34, n. 2, p. 49-53, 2001.

GIL, M. E. A. Inclusão digital e inclusão social. In: OMOTE, S. (Org.) Inclusão: intenção e realidade. Marilia: FUNDEPE, 2004. 
GONDIM, S. M. G. Grupos focais como técnica de investigação qualitativa: desafios metodológicos. Paidéia, v. 12, n. 24, p. 149-161, 2003.

GRASSELI, S. de M.; PAULA, A. H. Aspectos teóricos da atividade aquática para deficientes. Revista Digital, 2002.

GREGUOL, M. Natação Adaptada: em busca do movimento com autonomia. Barueri, SP: Manole, 2010.

GREVE, J. M. A.; CASTRO, A. W. Avaliação clínica e funcional da lesão medular - índices motores e sensitivos e funcionais utilizados. In: cap. 3, p.65-74. . Diagnóstico e tratamento da lesão medular espinhal. 1 ed. São Paulo: Roca, 2001.

GUYTON, A. C.; HALL, J. E. Tratado de fisiologia médica. Tradução de Bárbara de Alencar Martins. 11 ed. Rio de Janeiro: Elsevier, 2006. 1115 p. Título do original: Textbook of Medical Physiology.

KAMPS, D.; ROYER, J.; DUGAN, E.; KRAVITS, T.; GONZALEZ-LOPEZ, A.; GARCIA, J.; CARNAZZO, K.; MORRISON, L.; KANE, L. G. Peer training to facilite social interaction for elementary students with autism and their peers. Exceptional Children, v. 68, n. 2, p. 173-187, 2002.

LLORET, M. Natação Terapêutica. Rio de Janeiro. Sprint, 2003.

MACIEL, M. R. C. Portadores de deficiência: a questão da inclusão social. São Paulo em Perspectiva, v. 14, n. 2, p. 51$56,2000$.

MAIA, A. C. B. A importância das relações familiares para a sexualidade e a autoestima de pessoas com deficiência física. Psicologia. com. pt-O Portal dos Psicólogos, v. 1, 2010.

MARTINS, I. L. Educação tutorial no ensino presencial: uma analise sobre o PET. Brasília: Ministério da Educação, 2007.

MATTOS, E. Pessoa Portadora de Deficiência Física (motora) e as Atividades Físicas, Esportivas, Recreativas e de Lazer. In: PEDRINELLI, V. J. Educação física e desporto para pessoas portadoras de deficiência. Brasília: MEC/SEDES, 1994.

MINAYO, M. C. de Souza et al. Pesquisa social: teoria, método e criatividade. São Paulo, Vozes, 2013.

MINISTÉRIO DA SAUDE (BR). Secretaria de Políticas de Saúde. Política nacional de redução da morbimortalidade por acidentes e violência. Rev Saúde Pública, v. 34, n. 4, p. 427-30, 2000.

NABEIRO, M; LIBERMAN, L. J.; WISKOCHIL, B. O colega tutor (peer tutor) na educação física inclusiva. In: ANAIS DO I CONGRESSO DE ATIVIDADE MOTORA ADAPTADA. PUCRS, Porto Alegre, 2002. Anais... Porto Alegre, 2002.

ORLANDO, P. D’A. O colega tutor de alunos com deficiência visual nas aulas de Educação Física. São Carlos, UFSCAR, 2010.

PEREIRA, V. de A.; GARCEZ, E. M. Aspectos emocionais da paralisia cerebral na natação adaptada. EFDeportes.com, Revista Digital. Buenos Aires, año 15, n. 148 set. 2010. Disponível em: <http://www.efdeportes.com>. Acesso em: 20 fev. 2016.

PERRENOUT, P. Construir as competências desde a escola. Porto Alegre: Artmed, 1999.

RODRIGUES, D. A educação física perante a educação inclusiva: reflexões conceptuais e metodológicas. Boletim da Sociedade Portuguesa de Educação Física. v. 23/24, p. 73-81, 2003.

SANTOS, L.; VEIGA, F.; PEREIRA, A. Bem-estar, Sintomas emocionais e Dificuldades Interpessoais dos Estudantes do Ensino Superior. In: ACTAS DO VII SIMPÓSIO NACIONAL DE INVESTIGAÇÃO EM PSICOLOGIA, p. 103-115, 2012. Anais. 2012. 
SCHMITZ, T. J. Lesão medular traumática. In: O'SULLIVAN, S. B.; SCHMITZ, T. J. Fisioterapia: Avaliação e Tratamento. Tradução de Fernando Gomes do Nascimento. 4 ed. São Paulo: Manole, 2004. cap. 27, p. 873-901. Título do original: PhysicalRehabilitation: AssessmentandTreatment.

SECO, G. M. D. S. B.; CASIMIRO, M. C. S. M.; PEREIRA, M. I. A. R.; DIAS, M. I. P. S.; CUSTÓDIO, S. M. R. Para uma abordagem psicológica da transição do ensino secundário para o ensino superior: pontes e alçapões. Leiria: Instituto Politécnico de Leiria, 2005.

SOUZA, C. A.; SPANHOL, L, F. J.; LIMAS, J. C. O.; CASSOL M . P. Tutoria na educação a distância. 2004. Disponível em: <http://www.abed.org.br/congresso 2004/ por/htm/088-tc-c2.htm>. Acesso em :10 de jan. 2016.

SOUZA, J; MARTINS, M. F. A. Amálgama entre o professor inclusivo e o universo da educação física. Revista Educação Especial, v. 26, n. 46. 2013.

TOPPING K. Tutoria Academia Internacional de Educação. UNESCO Série Práticas Educativas: Departamento Internacional de Educação, 2000.

TOURNAKI, N.; CRISCITIELLO, E. Using peer tutoring as a successful part of behavior management. Teaching Exceptional Children, v. 36, n. 2, p. 22-29, 2003.

VAUGHN, S.; SCHUMM, J. S.; SINAGUB, J. M. Focus group interviews in education and psychology. London: Sage, 1996.

WALLACE, S.; GRAVELLS, J. Professional development. lifelong learning sector: Mentoring. Exeter: Learning Matters, 2005. 